http://jmscr.igmpublication.org/home/ ISSN (e)-2347-176x ISSN (p) 2455-0450

crossref DOI: https://dx.doi.org/10.18535/jmscr/v8i10.41

\title{
A Rare Case of Epithelioid Hemangioma of Orbit: A Challenge to Both Ocular Pathologist and Ophthalmologist
}

\author{
Authors \\ Soumitra Das ${ }^{1 *}$, Abhisek Lath ${ }^{2}$, Tushar Kanti Das ${ }^{3}$ \\ Department of Pathology, R.G. Kar Medical College \& Hospital \\ *Corresponding Author \\ Soumitra Das
}

\begin{abstract}
Epithelioid Hemangioma is a vascular lesion with controversial etiology, divided between reactive reaction and neoplastic origin. It is mostly situated around the temporal regions of head and neck. In this case report we present a rare case of an adult male who presented with an orbital lesion which was clinicoradiologically diagnosed as dermoid but was histopathologically diagnosed as Epithelioid Hemangioma

Keywords: Epithelioid Hemangioma, orbital lesion.
\end{abstract}

\section{Introduction}

Epithelioid hemangioma, also known as angiolymphoid hyperplasia with eosinophilia, has been a controversial lesion as it is considered as a reactive proliferation or a neoplastic process involving the mesenchymal element, mostly around the ear and temporal region. It most frequently occurs in the third to fifth decade of life. No gender predilection is noted. In this article we present a case of a 52 year male who presented with a mass in the medial aspect of left orbit for three months. It was provisionally diagnosed as a case of left eye Dermoid at the junction of frontonasal bone, but was finally diagnosed as Epithelioid Haemangioma with Eosinophilia.

\section{Case Report}

A 52 year male presented to the ophthalmology clinic with a mass in the medial aspect of left orbit. Vision was normal in the left eye whereas the perception of light was negative in the right eye due to prior trauma.

The CT scan of orbit revealed a space occupying lesion in the upper medial aspect of left orbit. The patient underwent an excision of the mass and the specimen was sent to the Department of Pathology for histopathological examination.

\section{Pathological Findings}

On macroscopy, a nodular mass was noted, measuring $1 \mathrm{~cm}$ in maximum dimension. On microscopy, proliferation of vascular channels was noted, along with dense inflammatory cell infiltration comprising lymphoid cells and rich in eosinophils. The vascular spaces were lined by plump-appearing (epithelioid) endothelial cells with mild pleomorphism, hyperchromatic nuclei, copious eosinophilic cytoplasm, and inconspicuous nucleoli. 


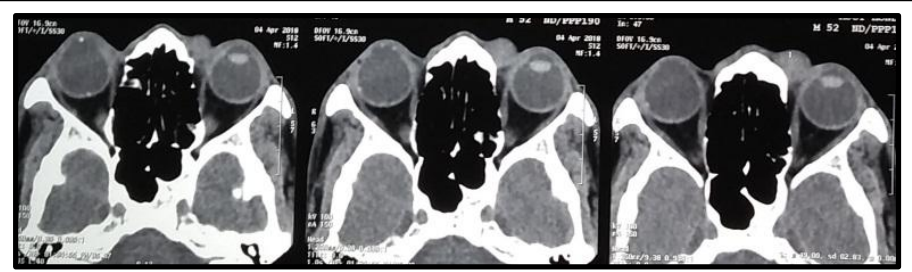

Figure 1: CT scan of orbit showing a space occupying lesion in the left orbit

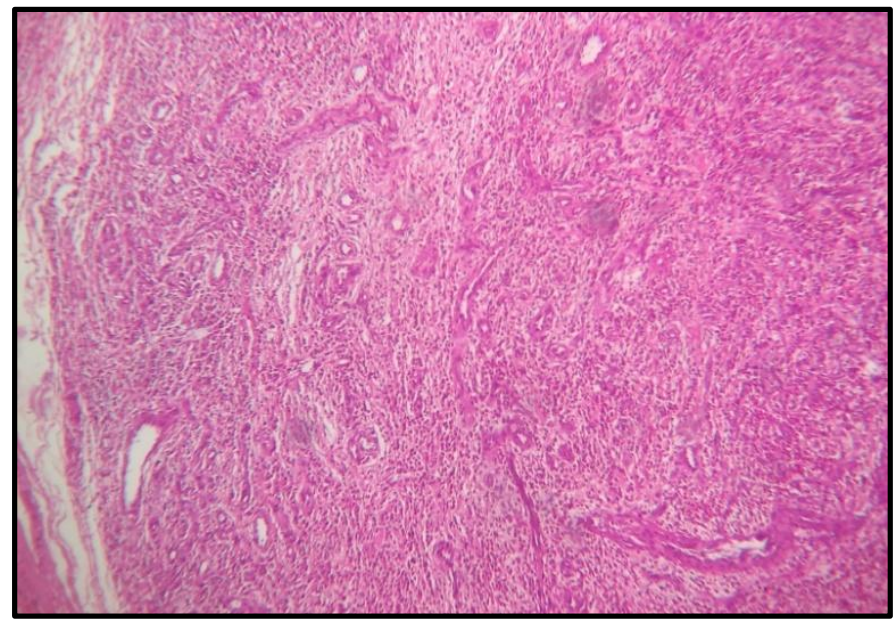

Figure 2: Low power view of the tissue section (H\&E: 100X)

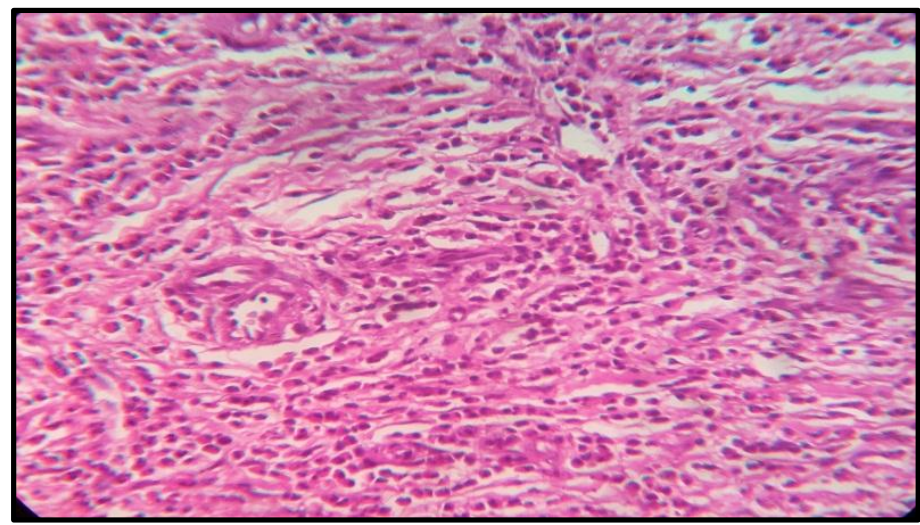

Figure 3: High power view of the tissue section (H\&E: 400X)

\section{Discussion}

Epithelioid hemangioma often presents as a subcutaneous proliferation with a predilection for the external ear (auricle and external canal), as well as other head and neck sites, including the scalp and forehead. ${ }^{1,2,3}$ Epithelioid hemangiomamost frequently occurs in the third to fifth decade of life. No gender predilection is evident. The symptoms include pruritus and bleeding following scratching. Regional lymphadenopathy and peripheral eosinophilia are uncommon, but they may be present. Hormonal influences may play a role in some cases, as the association with pregnancy in some patients and the age and gender distribution of the disease may suggest. Human herpesvirus- 8 (HHV8) has not been identified in association with Epithelioid hemangioma ${ }^{5,6,7}$. Local surgical excision or desiccation is the treatment of choice, and these are curative. Recurrences are occasionally seen. Medical regimens, including intralesional or systemic steroids, have been used with some success in treating the symptoms, but they have not beencurative.

Epithelioid hemangioma is characterized by single or multiple, pink to red-brown indurated cutaneous papules or subcutaneous nodules. These lesions measure from a few millimeters to $1 \mathrm{~cm}$ in diameter. Clusters of papules may coalesce to form large, plaque-like lesions. ${ }^{1,2}$ Histologically, Epithelioid hemangioma is characterized by a nodular vascular proliferation that is accompanied by a variably dense lymphoid infiltrate that is rich in eosinophils. The process is circumscribed but not encapsulated, and it may involve the subcutis, dermis, or both. The vascular component varies in size from capillary to medium-sized arteries and veins, and the vascular spaces are lined by plump- appearing (epithelioid) endothelial cells with mild pleomorphism, hyperchromatic nuclei, copious eosinophilic cytoplasm, and inconspicuous nucleoli ${ }^{1,4,8}$. Increased mitotic activity and moderate to marked nuclear pleomorphism are not usually seen in Epithelioid hemangioma. Frequently, the endothelial cells protrude into the vessel lumen in a "hobnail" fashion, creating a cobblestone- like appearance $^{7}$. A lobular arrangement of the proliferating vessels, as is seen in hemangiomas, may be evident; however, the distribution of vessels is more haphazard in some lesions. The vessels vary from irregular, poorly canalized, thin-walled spaces to rounded, well-formed vessels with thickened walls. In some cases, evidence of disruption or damage to some of the involved vessels is present. Origin from a small artery or vein is common but may be dependent on adequate sampling. It is common for the entire lesion to be intravascular ${ }^{5,6}$. 
Surrounding the vascular proliferation, a prominent inflammatory infiltrate is commonly seen including mature lymphocytes, histiocytes, and eosinophils. Ocassionally, eosinophils may be few or absent. The endothelial cells in Epithelioid hemangioma are immunoreactive for CD31, ERG, and to a lesser extent CD34. Staining for glucose transporter protein 1 (glut-1) is typically absent. Rarely, cytokeratin reactivity has been reported ${ }^{9,10}$. Intravascular Epithelioid hemangioma s differ from "conventional" forms by virtue of their predominant spindle cell component.

\section{Conclusion}

Epithelioid hemangioma, also known as angiolymphoid hyperplasia with eosinophilia (alhe), has been a controversial lesion with regard to its classification (reactive proliferation or neoplastic process) and its relationship to Kimura disease. although a reactive etiology especially secondary to trauma has been proposed, a neoplastic origin is favored. Epithelioid hemangioma is considered to represent the benign end of the spectrum of vascular tumors characterized by epithelioid endothelial cells, many of which are rich in lymphocytes and eosinophils. The malignant end of the spectrum includes epithelioid hemangioendothelioma and epithelioid angiosarcoma.

\section{References}

1. Barnes L, Koss W, Nieland ML. Angiolymphoid hyperplasia with eosinophilia: a disease that may be confused with malignancy. Head Neck Surg 1980;2:425-434.

2. Olsen TG, HelwigEB. Angiolymphoid hyperplasia with eosinophilia. A clinicopathologic study of 116 patients. J Am Acad Dermatol1985;12:781-796.

3. Fetsch JF, Weiss SW. Observations concerning the pathogenesis of epithelioid hemangioma (angiolymphoid hyperplasia). Mod Pathol1991;4:449-455.

4. Rosai J, Gold J, Landy R. The histiocytoid hemangioma: a unifying concept embracing several previously described entities of skin, soft tissues, large vessels, bone and heart. HumPathol1979;10:707-730.

5. Calonje JE, Fletcher CDM. Epithelioid hemangioma (angiolymphoid hyperplasia with eosinophilia). In Fletcher CDM, ed. Diagnostic Histopathology of Tumors. 4th ed. Philadelphia: Elsevier Saunders, 2013:54-55.

6. Fetsch JF. Epithelioid haemangioma. In Fletcher CDM, Bridge JA, Hogendoorn PCW, Mertens F, eds. WHO Classification of Tumours of Soft Tissue and Bone. Lyon: IARC, 2013:141-142.

7. Chun SI, Goo H. Kimura's disease and angiolymphoid hyperplasia with eosinophilia: clinical and histopathologic differences. J Am Acad Dermatol 1992;27:954-958.

8. Googe PB, Harris NL, Mihm MC. Kimura's disease and angiolymphoid hyperplasia with eosinophilia: two distinct histopathological entities. J Cutan Pathol1987;14:263-271.

9. O'Connell JX, Kattapuram SV, Mankin HJ, et al. Epithelioid hemangioma of bone. A tumor often mistaken for low-grade angiosarcoma or malignant hemangioendothelioma. Am J Surg Pathol 1993;17:610-617.

10. Fetsch JF, Sesterhenn I, Miettinen M, et al. Epithelioid hemangioma of the penis: a clinicopathologic and immunohistochemical analysis of 19 cases, with special reference to exuberant examples often confused with epithelioid hemangioendothelioma and epithelioid angiosarcoma. Am J Surg Pathol2004; 28:523-533. 